\title{
Low Temperature Chemoselective Hydrogenation of Aldehydes over a Magnetic Pd Catalyst
}

\author{
Anqiu Liu ${ }^{1} * \mathbb{C}^{\mathbb{D}}$, Xiaochen Wang ${ }^{1}$, Daming Gao ${ }^{1}$, Le Wang ${ }^{1}$, Junjie Cheng ${ }^{1}$, An Wang ${ }^{1}$ and \\ Zehui Zhang ${ }^{2, *}$ \\ 1 Department of Chemistry and Materials Engineering, Hefei University, Hefei 230601, China; \\ wxc@hfuu.edu.cn (X.W.); dmgao@hfuu.edu.cn (D.G.); jhonwl@foxmail.com (L.W.); \\ Cjj337163802@163.com (J.C.); wangan_2019@163.com (A.W.) \\ 2 Key Laboratory of Catalysis and Materials Sciences of the Ministry of Education, \\ South-Central University for Nationalities, Wuhan 430074, China \\ * Correspondence: liuaq@hfuu.edu.cn (A.L.); zehuizh@mail.ustc.edu.cn (Z.Z.); \\ Tel.: +86-027-67842040 (Z.Z.); Fax: +86-411-84379600 (Z.Z.)
}

Received: 20 February 2019; Accepted: 24 April 2019; Published: 29 April 2019

\begin{abstract}
Chemoselective hydrogenation of aldehydes with heterogeneous catalysts under mild conditions is of great importance but remains a major challenge. Herein, an efficient strategy was developed for low temperature chemoselective hydrogenation of aldehydes with broad substrate scope over a magnetic material supported palladium catalyst $\left(\gamma-\mathrm{Fe}_{2} \mathrm{O}_{3} @ \mathrm{HAP}-\mathrm{Pd}\right)$. Aldehydes bearing various reducible functional groups readily underwent hydrogenation to give the corresponding primary alcohols with moderate to excellent yield at room temperature in aqueous solutions. The Hammett equation revealed that the hydrogenation of aromatic aldehydes proceeded via an anionic intermediate. Additionally, when the temperature increased to $70^{\circ} \mathrm{C}$, toluene was obtained by the deoxygenation of benzaldehyde in excellent yield. Furthermore, the $\gamma-\mathrm{Fe}_{2} \mathrm{O}_{3} @ \mathrm{HAP}-\mathrm{Pd}$ could be recycled up to six times without loss of activity and metal leaching.
\end{abstract}

Keywords: selective hydrogenation; aldehydes; Pd catalysts; mild conditions

\section{Introduction}

Catalytic hydrogenation reactions are one of the most important processes, which are key routes for the production of numerous bulk products and intermediates in the chemical industry [1]. In particular, the chemoselective reduction of aldehydes in the presence of reducible functional groups under mild conditions has been recognized as a major challenge [2-5]. Hence, there as been a growing focus on the purity of the hydrogenation of aldehydes in recent years.

The catalytic hydrogenation of aldehydes can be performed either using hydrogen or other hydrogen donors such as organic silanes [6-8] and alcohols [9]. Transfer hydrogenation of carbonyl compounds by organic silanes can be performed under very mild conditions in the presence of homogenous catalysts, but the use of organic silanes was neither cheap nor green due to the high cost of the organic silanes and the lower atom efficiency [7]. Alcohols especially iso-propanol had also been reported to be used for the transfer hydrogenation of carbonyl compounds [9]. However, these catalysts were usually not recyclable and required harsh reaction conditions [10,11]. Nonetheless, molecular hydrogen is a lower cost, much more atom-economic and cleaner reducing agent compared to the silanes. Therefore, the reduction of aldehydes with $\mathrm{H}_{2}$ represented one of the most efficient and atom-economical transformations.

Both heterogeneous and homogeneous catalysts had been used for the reduction of aldehydes with molecular hydrogen. Generally, reactions with homogeneous catalysts could be performed under 
relative mild conditions, as the homogeneous catalysts moved freely in the reaction solution [12-14]. Of particular note was that several kinds of homogeneous base metal catalysts had been discovered to be active for the hydrogenation of aldehydes under mild conditions. For example, Beller and co-workers demonstrated that manganese complexes could promote the aromatic carbonyl compounds into the corresponding alcohols under mild conditions $\left(60^{\circ} \mathrm{C}\right.$ and $10 \mathrm{bar} \mathrm{H}_{2}$ pressure) [14]. However, this method required the use of additional additives such as $t-\mathrm{BuONa}$, which is sensitive to the air and moisture. More importantly, it was difficult to recycle and reuse the homogeneous catalysts $[15,16]$.

To overcome the associated drawbacks of homogeneous catalysts [17-20], great effort has been devoted to the design of heterogeneous catalysts for the reduction of carbonyl groups at low temperature. Several kinds of metal catalysts have been reported to be active for the hydrogenation of carbonyl compounds into alcohols at low temperatures or hydrogen pressure. For example, Sekar and co-workers reported palladium nanoparticles (Pd-BNP) stabilized by a binaphthyl-backbone can be efficiently used for the chemoselective reduction of aldehydes in the presence of hydrogen at room temperature in water [17]. To further recycle the heterogeneous catalyst easily, a graphene-modified Ru catalyst was also reported to be active for the reduction of carbonyl groups into hydroxyl groups at a low temperature of $20^{\circ} \mathrm{C}$ and 40 bar $\mathrm{H}_{2}$ [18]. Acknowledging these important achievements, however, the range of chemoselective heterogeneous hydrogenation of aldehydes using molecular hydrogen in the presence of reducible functional groups was still quite limited [20], which restricted their application. For example, the Pd-BNP [17] could not reduce aliphatical dehydes and heteroaromatic aldehydes, while graphene-modified Ru [18] could not selectively reduce aldehydes from ketone. Indeed, to the best of our knowledge, there are no heterogeneous catalysts that can selectively hydrogenation of aldehydes bearing various reducible functional groups including halogen, ketone, ester, carbon-carbon double bond, amine, nitro, or cyano group at low temperature yet. Furthermore, the subsequent hydrogenolysis of the hydroxyl group into the saturated groups is an even greater challenge [21], which is also very useful in the synthesis of value-added chemicals and liquid fuels. Therefore, it is important to continually develop efficient methods for the hydrogenation of aldehydes into corresponding alcohols or alkane under mild conditions with abroad substrate scope. In the present study, we tackle these problems with a new robust magnetic supported Pd catalyst.

In our previous work, we had successfully prepared a magnetic material supported Pd catalyst (abbreviated as $\gamma-\mathrm{Fe}_{2} \mathrm{O}_{3} @ \mathrm{HAP}-\mathrm{Pd}$ ) and found that the as-prepared $\gamma-\mathrm{Fe}_{2} \mathrm{O}_{3} @ \mathrm{HAP}-\mathrm{Pd}$ catalyst was active for the oxidation of 5-hydroxymethylfurfural into 2,5-furandicarboxylic acid [22-24]. As palladium catalysts have also been widely used as the catalysts to activate molecular $\mathrm{H}_{2}$ for reductive chemical reaction $[25,26]$, it is expected that the $\gamma-\mathrm{Fe}_{2} \mathrm{O}_{3} @ \mathrm{HAP}-\mathrm{Pd}$ is active for the reduction aldehydes under mild conditions.

\section{Experimental Section}

\subsection{Materials}

All other chemicals were purchased from Aladdin Chemicals Co. Ltd. (Beijing, China). All solvents were purchased from Sinopharm Chemical Reagent Co., Ltd. (Shanghai, China), and used directly.

\subsection{Catalyst Synthesis and Characterization}

The $\gamma-\mathrm{Fe}_{2} \mathrm{O}_{3} @ \mathrm{HAP}-\mathrm{Pd}$ catalyst was prepared and characterized as reported in our previous work [22]. The synthetic route maybe summarized as follows (Scheme 1), $\mathrm{Fe}^{2+}$ and $\mathrm{Fe}^{3+}$ ions in alkaline solution were co-precipitated under nitrogen to produce $\mathrm{Fe}_{3} \mathrm{O}_{4}$ nanoparticles. These were then coated with $\mathrm{HAP}$, formed fromCa ${ }^{2+}$ and $\mathrm{PO}_{4}{ }^{3-}$ at $\mathrm{pH} 11$, and the product calcined at $300{ }^{\circ} \mathrm{C}$ for $3 \mathrm{~h}$ to produce $\gamma-\mathrm{Fe}_{2} \mathrm{O}_{3} @ \mathrm{HAP}$. The brown powder $\gamma-\mathrm{Fe}_{2} \mathrm{O}_{3} @ \mathrm{HAP}-\mathrm{Pd}^{2+}$ was prepared by cation exchange of $\mathrm{Ca}^{2+}$ in $\gamma-\mathrm{Fe}_{2} \mathrm{O}_{3} @ \mathrm{HAP}$ with $\mathrm{Pd}^{2+}$, and the $\mathrm{Pd}^{2+}$ reduced by $\mathrm{NaBH}_{4}$ inethanol to generate the $\gamma-\mathrm{Fe}_{2} \mathrm{O}_{3} @ \mathrm{HAP}-\mathrm{Pd}(0)$ catalyst. After addition of $\mathrm{NaBH}_{4}$, the color of the catalyst changed immediately from brown to dark grey, confirming that the $\mathrm{Pd}^{2+}$ in $\gamma-\mathrm{Fe}_{2} \mathrm{O}_{3} @ \mathrm{HAP}-\mathrm{Pd}^{2+}$ had been successfully 
reduced to $\operatorname{Pd}(0)$ nanoparticles. The content of Pd was determined as $2 \mathrm{wt} \%$ by ICP- OES analysis, while the particle size distribution of Pd nanoparticles was determined as $2.8 \mathrm{~nm}$ by TEM [22].

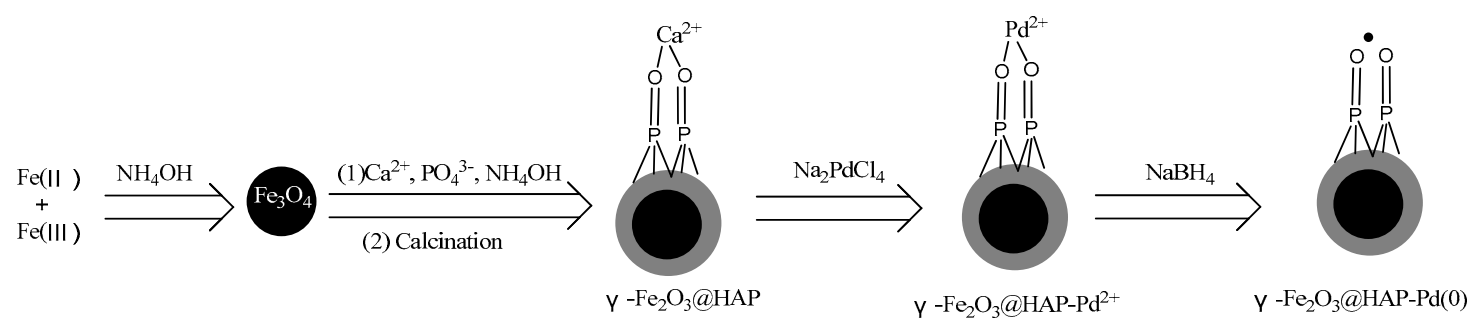

Scheme 1. Schematic illustration of the preparation of the $\gamma-\mathrm{Fe}_{2} \mathrm{O}_{3} @ \mathrm{HAP}-\mathrm{Pd}(0)$ catalyst.

\subsection{Generalprocedure of the Reduction of Carbonyl Compounds}

The catalytic reduction of benzaldehyde was used as a model reaction. Typically, the reaction was performed in a stainless steel $40 \mathrm{~mL}$ Parr batch reactor. Typically, benzaldehyde $(1 \mathrm{mmol})$, $\gamma-\mathrm{Fe}_{2} \mathrm{O}_{3} @ \mathrm{HAP}-\mathrm{Pd}(20 \mathrm{mg})$, and $\mathrm{H}_{2} \mathrm{O}(10 \mathrm{~mL})$ were charged into the reactor. The reactor was purged with $\mathrm{H}_{2}$ by 5 times to completely remove the air in the reactor and the reaction solution, then charged with 2.5 bar $\mathrm{H}_{2}$ at room temperature. The reactor with $\mathrm{H}_{2}$ was heated to $70{ }^{\circ} \mathrm{C}$ within $4 \mathrm{~min}$, commencing the catalytic reaction. The reaction was maintained at $70{ }^{\circ} \mathrm{C}$ for $12 \mathrm{~h}$, while the reaction mixture was mechanically stirred at $1000 \mathrm{rpm}$. The reaction was stopped by cooling the reactor to room temperature and depressurized. The reaction mixture was extracted by ethyl acetateandanalyzed by gas chromatography (GC) using ethylbenzene as the internal standard.

\subsection{Analyticmethods}

Quantities of the products was analyzed by a GC (7890F) instrument with a crosslinked capillary HP- 5 column $(30 \mathrm{~m} \times 0.32 \mathrm{~mm} \times 0.4 \mathrm{~mm})$ equipped with a flame ionization detector. The temperature of the column was initially kept at $80{ }^{\circ} \mathrm{C}$ for $3 \mathrm{~min}$, and then increased at a rate of $20{ }^{\circ} \mathrm{C} \mathrm{min}-1$ to $220^{\circ} \mathrm{C}$. Products were identified by comparison of the retention time of the unknown compounds with those of standard compounds and quantified based on the internal standard method. The products were confirmed by GC-MS (Agilent 7890A GC/5973 MS, HP-5 column). Some products with reducible functional groupswereseparated and further confirmed by $\mathrm{H}^{1} \mathrm{NMR}$ (BrukerAVANCEIII, $400 \mathrm{MHz}$ ).

Aldehyde conversion and Alcoholselectivitywere defined as follows:

Aldehyde conversion $=$ moles of convertedaldehyde $/$ moles of starting aldehyde $\times 100 \%$

Alcohol yield $=$ moles of generated alcohol $/$ moles of starting aldehyde $\times 100 \%$

Alcohol selectivity $=$ alcohol yield/aldehyde conversion $\times 100 \%$

\section{Results and Discussion}

\subsection{Effect of the Reaction Solvents on the Hydrogenation of Benzaldehyde}

Generally speaking, the reaction solvent playeda key role in the chemical reaction, as different solvents had different properties such as the polarity, dielectric constant, and steric hindrance [27]. Therefore, the hydrogenation of benzaldehyde was initially carried out in various solvents catalyzed by $\gamma-\mathrm{Fe}_{2} \mathrm{O}_{3} @ \mathrm{HAP}-\mathrm{Pd}$ to study to the solvent effect. As listed in Table 1, it was noted the conversion of benzaldehyde over the $\gamma-\mathrm{Fe}_{2} \mathrm{O}_{3} @ \mathrm{HAP}-\mathrm{Pd}$ catalyst was greatly affected by the reaction solvents, while the selectivity was all above $90 \%$. The lowest benzaldehyde conversion was observed in hexane with the weakest polarity (Table 1, Entry 1). The conversion of benzaldehyde increased from $34.2 \%$ in tetrahydrofuran (THF) to $56.9 \%$ in iso-propanol, further greatly increasing to $95.6 \%$ in ethanol (Table 1 , Entries 3 4). The possible reason should be that the $\gamma-\mathrm{Fe}_{2} \mathrm{O}_{3} @ \mathrm{HAP}-\mathrm{Pd}$ catalyst can well dispersed in polar solvents instead of nonpolar solvents, as the surface of the $\gamma-\mathrm{Fe}_{2} \mathrm{O}_{3} @ \mathrm{HAP}-\mathrm{Pd}$ catalyst was 
a layer inorganic HAP, which was hydrophilic. Hence, the higher polarity of the solvents led to the higher conversion of benzaldehyde. Interestingly, the best result was attained in water with the highest benzaldehyde conversion of $98.7 \%$ (Table 1, Entry 5), although benzaldehyde was less soluble in water than in ethanol. We presumed that a stronger hydrogen bonding between water and benzaldehyde should benefit the hydrogenation reactions $[28,29]$. It was noted that benzyl alcohol was attained in an almost quantitative yield at room temperature and atmospheric $\mathrm{H}_{2}$ pressureafter reacted for $4 \mathrm{~h}$ (Table 1, Entry 6), which was capable with the Pd-BNP (Table 1, Entry 7) [17].

Table 1. Results of the hydrogenation of benzyl aldehyde in different solvents a ${ }^{\text {. }}$

\begin{tabular}{|c|c|c|c|c|}
\hline Entry & Catalyst & Solvent & $\begin{array}{c}\text { Con. of Benzyl } \\
\text { Aldehyde }(\%)\end{array}$ & $\begin{array}{l}\text { Sel. of Benzyl } \\
\text { Alcohol(\%) }\end{array}$ \\
\hline 1 & $\gamma-\mathrm{Fe}_{2} \mathrm{O}_{3} @ \mathrm{HAP}-\mathrm{Pd}$ & Hexane & 17.2 & 90.1 \\
\hline 2 & $\gamma-\mathrm{Fe}_{2} \mathrm{O}_{3} @ \mathrm{HAP}-\mathrm{Pd}$ & THF & 34.2 & 90.9 \\
\hline 3 & $\gamma-\mathrm{Fe}_{2} \mathrm{O}_{3} @ \mathrm{HAP}-\mathrm{Pd}$ & $i-\mathrm{PrOH}$ & 56.9 & 99.0 \\
\hline 4 & $\gamma-\mathrm{Fe}_{2} \mathrm{O}_{3} @ \mathrm{HAP}-\mathrm{Pd}$ & $\mathrm{EtOH}$ & 95.6 & 96.5 \\
\hline 5 & $\gamma-\mathrm{Fe}_{2} \mathrm{O}_{3} @ \mathrm{HAP}-\mathrm{Pd}$ & $\mathrm{H}_{2} \mathrm{O}$ & 98.7 & 96.4 \\
\hline $6^{b}$ & $\gamma-\mathrm{Fe}_{2} \mathrm{O}_{3} @ \mathrm{HAP}-\mathrm{Pd}$ & $\mathrm{H}_{2} \mathrm{O}$ & 100 & $>99$ \\
\hline $7^{\mathrm{c}}$ & Pd-BNP & $\mathrm{H}_{2} \mathrm{O}$ & \multicolumn{2}{|c|}{$90^{\mathrm{d}}$} \\
\hline
\end{tabular}

\footnotetext{
${ }^{a}$ Reaction condition: benzyl aldehyde ( $\left.1 \mathrm{mmol}\right), 10 \mathrm{mg} \gamma-\mathrm{Fe}_{2} \mathrm{O}_{3} @ \mathrm{HAP}-\mathrm{Pd}$ catalyst ( $2 \mathrm{wt}$ \% by ICP-OES analysis); $\mathrm{S} / \mathrm{C}=530$, solvent $(10 \mathrm{~mL}), \mathrm{H}_{2}(10$ bar $), 25^{\circ} \mathrm{C}, 1 \mathrm{~h}$.

${ }^{\mathrm{b}} \mathrm{S} / \mathrm{C}=530, \mathrm{H}_{2}(1 \mathrm{bar}), 25^{\circ} \mathrm{C}, 4 \mathrm{~h}$.

${ }^{c}$ from ref $15, \mathrm{~S} / \mathrm{C}=100, \mathrm{H}_{2}(1 \mathrm{bar}), 25^{\circ} \mathrm{C}, 6 \mathrm{~h}$.

${ }^{\mathrm{d}}$ Isolated yield.
}

\subsection{Effect of the Hydrogen Pressure on the Hydrogenation of Benzaldehyde}

The effect of hydrogen pressure on the reduction of benzaldehyde was also studied. As shown in Figure 1, the conversion of benzaldehyde increased with the increasing of the hydrogen pressure. As the hydrogen pressure increasing from 1 bar to 10 bar, the conversion of benzaldehyde increased from $36.8 \%$ to $100 \%$ after reacted for $1 \mathrm{~h}$ at room temperature. The increasing hydrogen pressure might result in the increasing hydrogen concentration in the reaction solution, which accelerated the reaction. However, it seemed that the selectivity of benzyl alcohol wasinsensitive to the hydrogen pressure, which remained $>95 \%$ under different hydrogen pressures. Considered the reaction efficiency, we chose 10 bar as the optimizedhydrogen pressure.

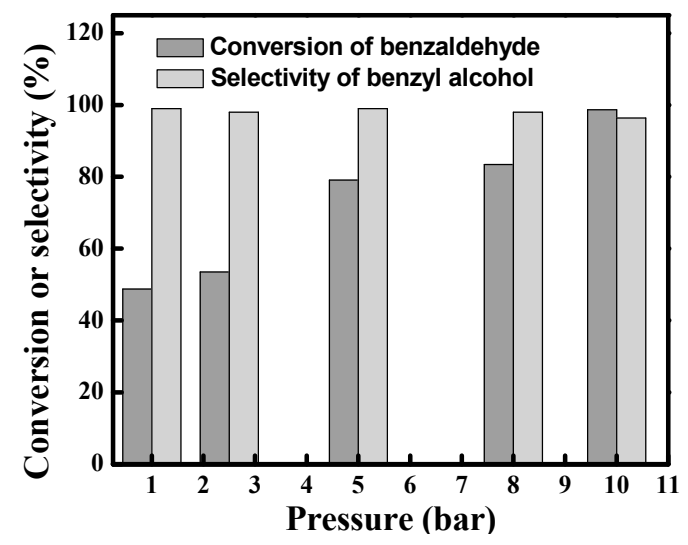

Figure 1. Results of the reduction of benzaldehyde at different hydrogen pressure. Reaction conditions: benzaldehyde (1 mmol), 2 wt.\% $\gamma-\mathrm{Fe}_{2} \mathrm{O}_{3} @ \mathrm{HAP}-\mathrm{Pd}$ catalyst $(10 \mathrm{mg}), \mathrm{H}_{2} \mathrm{O}(10 \mathrm{~mL}), 25^{\circ} \mathrm{C}, 1 \mathrm{~h}$.

\subsection{Substrate Scope of the Reduction of Aldehydes to Alcohols}

After achieving the best reaction conditions, thescope of the hydrogenation of various aldehydes wasinvestigated and the results were summarized in Table 2. To our delight, aldehydes bearing various 
kinds of labile groups on the aromatic ringwere well tolerated and gave the corresponding alcohols with moderate to excellent yields in $1-21 \mathrm{~h}$ at room temperature. It wasinterestingly to note that the reaction rate was accelerated in presence of electron-withdrawing groups such as $-\mathrm{CF}_{3},-\mathrm{F},-\mathrm{Cl}$, -Br, $-\mathrm{NO}_{2}$, and -CN (Entries 1-6, Table 2). 4-(Trifluoromethyl) benzaldehyde, 4-fluorobenzaldehyde, and 4-chlorobenzaldehyde were converted to the corresponding alcohol smoothly in $4 \mathrm{~h}$ with nearly quantitative yields; however, debromination occurred when 4-bromobenzaldehyde used as substrate (Entry 4, Table 2). Interestingly, our catalyst couldselectivelyreduce aldehydes, while other carbonyl compounds such like ester or ketone groups were well preserved (Entries 7-8, Table 2). Lower reaction rates were observed for substrates with electron-donating substituted groups than those with electron-withdrawing substituents (Entries 10-14 Table 2 vs. Entries 1-8 Table 2). Longer reaction times (5-21 h) were needed to get good to excellent yields of corresponding alcohols. These results suggested that the electron state of other functional groups controls the activation state of the intermediate in this reaction. The reaction rate increasing with the electron-withdrawing groups indicated that electron went towards the aromatic ring in intermediates [30]. Moreover, all fused-ring aromatic aldehyde (2-naphthaldehyde), the heterocyclic aldehyde (4-pyridinecarboxaldehyde), aliphatic aldehydes (heptanal), and $\alpha, \beta$-unsaturated aldehydes (cinnamaldehyde), which were reported unreactive by Sekar [17], could be reduced to corresponding alcohols with good to excellent selectivity by our method(Entries 15-19, Table 2).This means that our methodhada broad scope for aldehydes.

It was worth noting that our method providedan economical and environmentally-friendly protocol for the hydrogenation of aldehydes into alcohols, because of the use of cheap and green solvent of water, and the mild reaction conditions. Our method could selectively hydrogenation of aldehydes bearing all kinds of reducible functional groups suchas ketone, halogen, nitro, amine, or cyano groups with moderate to excellent yield, which expanded the scope of substrates for this kind of reaction and could be very useful in organic synthesis.

To get more insights into the catalytic reduction of aldehydes over the $\gamma-\mathrm{Fe}_{2} \mathrm{O}_{3} @ \mathrm{HAP}-\mathrm{Pd}$ catalyst, the reaction rates were studied in detail using the Hammett equation as an empirical rule. The results were shown in Figure 2. The hydrogenation rate of the substituted benzaldehyde showed a reasonable linear Hammett correlation and a Hammett value of 1.59 was obtained, indicating that the reduction of the aldehyde group to a hydroxy group was substituent-sensitive and proceeded via an anionic intermediate [30,31]. According to the results of Hammett equation, We predicted the reaction mechanism as follows: (1) hydrogen molecular cleaved by heterolysisin the presence of catalystand afford a $\mathrm{H}^{-}$and a $\mathrm{H}^{+}$; (2) the $\mathrm{H}^{-}$reacted with aldehydes and gave the anionic intermediate $\mathrm{PhCH}_{2} \mathrm{O}^{-}$; (3) $\mathrm{PhCH}_{2} \mathrm{O}^{-}$reacted with proton and give the product $\mathrm{PhCH}_{2} \mathrm{OH}$.

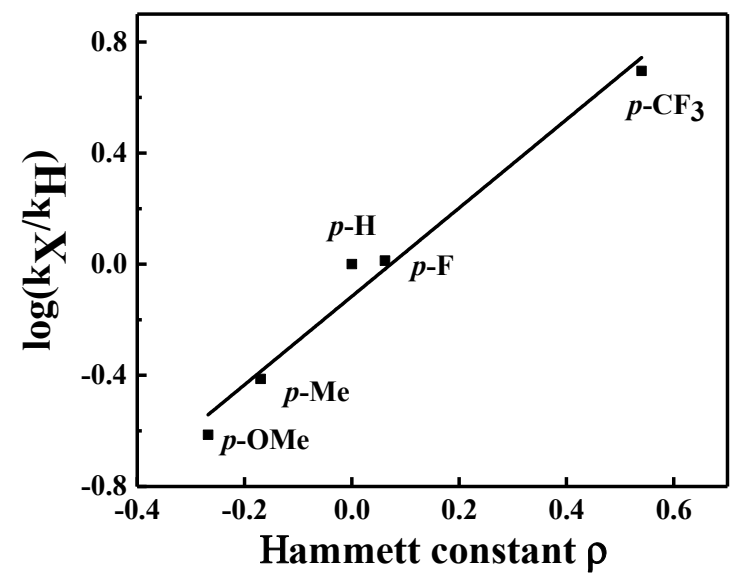

Figure 2. Correlation study for catalytic reduction of various aromatic aldehydes to the corresponding aromatic alcohols. Reaction conditions: substrate $(1 \mathrm{mmol}), \gamma-\mathrm{Fe}_{2} \mathrm{O}_{3} @ \mathrm{HAP}-\mathrm{Pd}(10 \mathrm{mg})$ catalyst, $25^{\circ} \mathrm{C}$, $\mathrm{H}_{2}$ (10 bar), $\mathrm{H}_{2} \mathrm{O}(10 \mathrm{~mL})$. 
Table 2. Substrate scope of the reduction of aldehydes to alcohols over $\gamma-\mathrm{Fe}_{2} \mathrm{O}_{3} @ \mathrm{HAP}-\mathrm{Pd}$ catalyst ${ }^{\mathrm{a}}$.

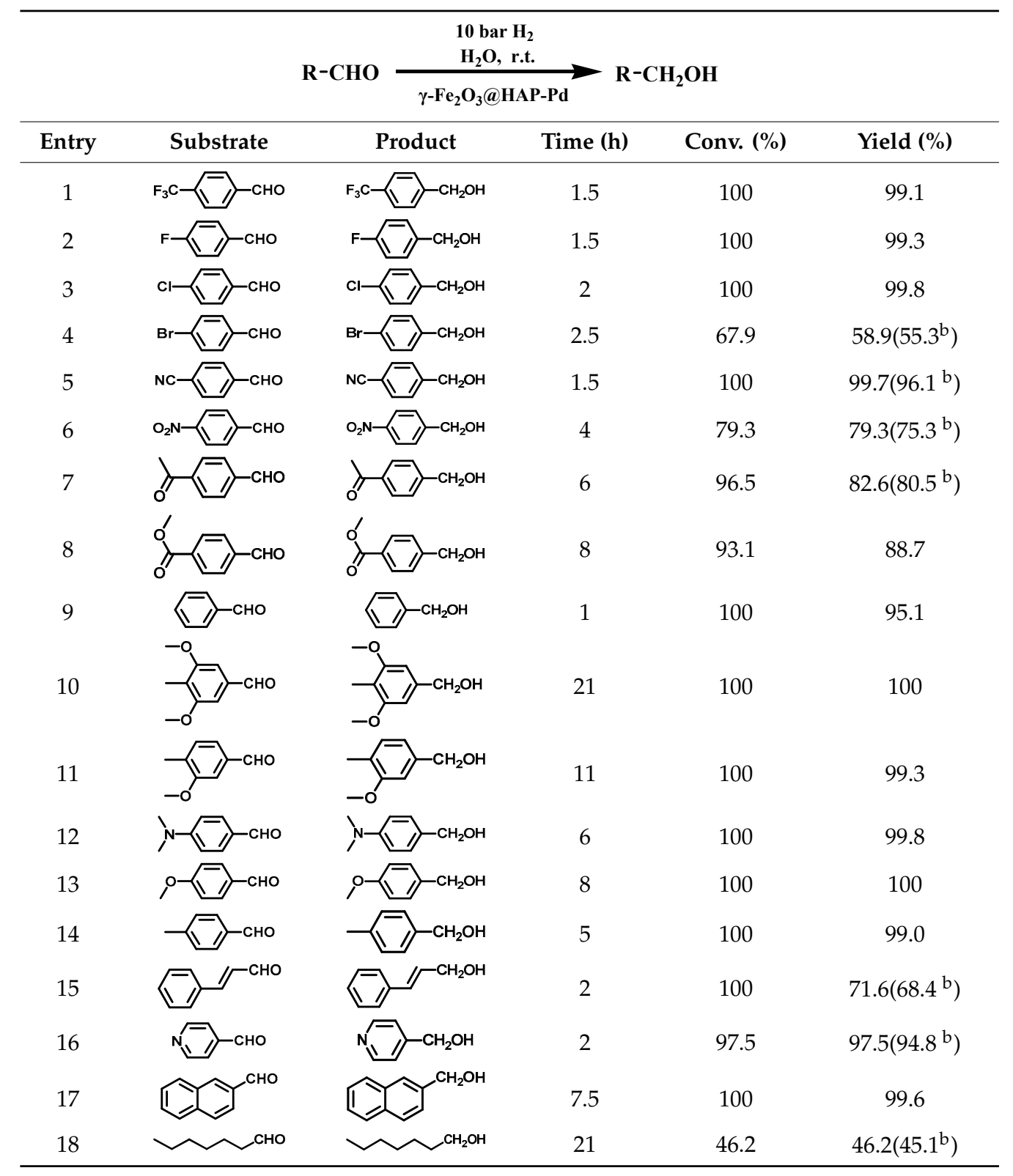

a Reaction conditions: substrate $(1 \mathrm{mmol}), \gamma-\mathrm{Fe}_{2} \mathrm{O}_{3} @ \mathrm{HAP}-\mathrm{Pd}(10 \mathrm{mg})$ catalyst, $25^{\circ} \mathrm{C}, \mathrm{H}_{2}(10 \mathrm{bar}), \mathrm{H}_{2} \mathrm{O}(10 \mathrm{~mL})$.

b Isolated yield.

\subsection{Effect of the Temperature on the Deoxygenation of Benzaldehyde}

We also tried to use this catalyst for the deoxygenation of benzaldehyde into the saturated compounds, which was also very useful in the synthesis of value-added chemicals and liquid fuels. As the hydrogenolysis of hydroxyl group wasmuch more difficult than the reduction of the carbonyl groups into alcohols, we performed the reduction of benzaldehyde at 2.5 bar and elevated temperatures, and the results wereshown in Figure 3. We couldfind that the reaction ratewas greatly affected by the reaction temperature. As the reaction temperature increased, the yield of toluene increased, while the yield of benzyl alcohol decreased. When the reaction temperature below $70^{\circ} \mathrm{C}$, the yield of toluene wasvery low in $12 \mathrm{~h}$, while the temperature exceeded $70{ }^{\circ} \mathrm{C}$, the yield of toluenecould reach to $95 \%$ in a shorter time (Table S3). These results showed that higher reaction temperature benefited the hydrogenolysis of hydroxyl group, indicating the activation energyofthehydrogenolysis 
of hydroxyl group is higher than the hydrogenation of the aldehyde group. At the reaction temperature of $130{ }^{\circ} \mathrm{C}$, toluene could be produced with an excellent yield of $97.9 \%$ in a short time of $1 \mathrm{~h}$ over the $\gamma-\mathrm{Fe}_{2} \mathrm{O}_{3} @ \mathrm{HAP}-\mathrm{Pd}$ catalyst, whichwascomparable with the reported homogeneous catalyst of $\mathrm{Ru}$-pincer complexes that promoted the deoxygenation of carbonyl groups at $130^{\circ} \mathrm{C}$ and 2 bar $\mathrm{H}_{2}$ [21].

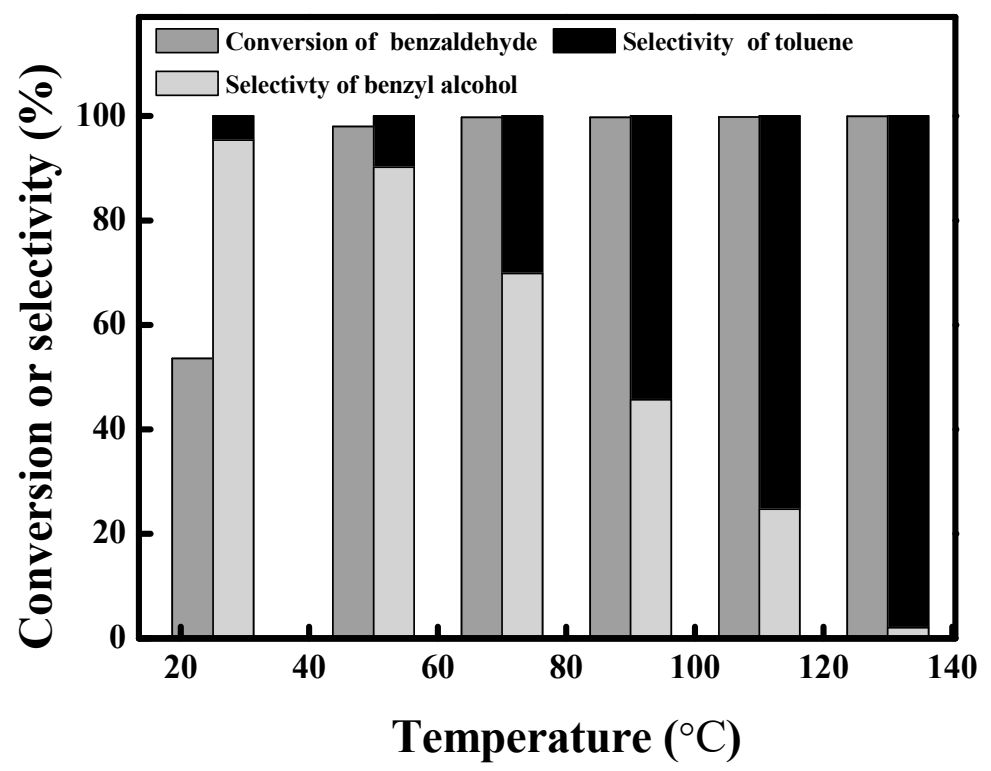

Figure 3. Results of the reduction of benzaldehyde at different temperatures. Reaction conditions: Benzaldehyde (1 mmol), 2 wt.\% $\gamma-\mathrm{Fe}_{2} \mathrm{O}_{3} @ \mathrm{HAP}-\mathrm{Pd}$ catalyst $(10 \mathrm{mg}), \mathrm{H}_{2} \mathrm{O}(10 \mathrm{~mL}), 2.5$ bar $\mathrm{H}_{2}, 1 \mathrm{~h}$.

\subsection{Time Course of the Product Distributions}

There were two pathways for the deoxygenation of aromatic aldehyde (Scheme 2): (A) hydrogenation/hydrogenolysis, and (B) direct hydrogenolysis of the $\mathrm{C}-\mathrm{O}$ bond. According to the results in Figure 4, benzaldehyde was almost completelyconsumedin $1 \mathrm{~h}$ with $68.8 \%$ toluene and $41.2 \%$ benzyl alcohol generated. As the reaction time was prolonged to $12 \mathrm{~h}$, the yield of benzyl alcohol gradually decreased from $41.2 \%$ to $0.4 \%$, meanwhile the yieldof toluene gradually increased from $68.8 \%$ to $99.6 \%$. Actually, as the reaction time increased, the yield of toluene of all the reactions at different reaction temperatures increased, while the yield of benzyl alcoholde creased (Table S3 and Figure 4), which means thatobtaining toluene as the final product of the successive pathway was just a question of time. Thus, we couldconclude that the deoxygenation of carbonyl groups over the $\gamma-\mathrm{Fe}_{2} \mathrm{O}_{3} @ \mathrm{HAP}-\mathrm{Pd}$ catalysts followed Pathway A in Scheme 2.

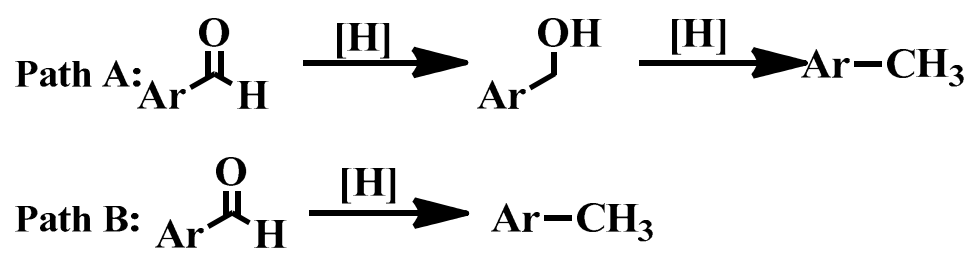

\section{Ar=Aromatic group}

Scheme 2. Reaction pathways for the deoxygenation of the aromatic aldehydes. 


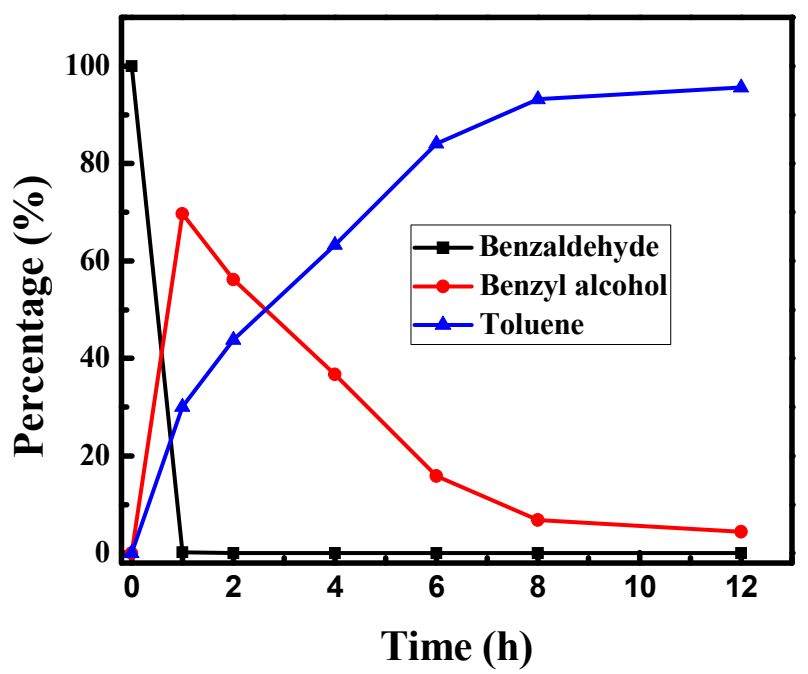

Figure 4. Time course of the deoxygenation of benzylaldehyde into toluene. Reaction conditions: benzylaldehyde (1 mmol), 2 wt. $\% \gamma-\mathrm{Fe}_{2} \mathrm{O}_{3} @ \mathrm{HAP}-\mathrm{Pd}$ catalyst $(10 \mathrm{mg}), \mathrm{H}_{2} \mathrm{O}(10 \mathrm{~mL}), 2.5 \mathrm{bar} \mathrm{H}_{2}, 70{ }^{\circ} \mathrm{C}$.

\subsection{Recycling of the $\gamma-\mathrm{Fe}_{2} \mathrm{O}_{3} @ H A P-P d$ Catalyst}

Finally, the stability of the $\gamma-\mathrm{Fe}_{2} \mathrm{O}_{3} @ \mathrm{HAP}-\mathrm{Pd}$ was also studied, and the recycling experiments were conducted (Figure 5). The hydrogenation of benzaldehyde was used as the model reaction, which was performed at room temperature and 10 bar $\mathrm{H}_{2}$ pressure. After reaction, the $\gamma-\mathrm{Fe}_{2} \mathrm{O}_{3} @ \mathrm{HAP}-\mathrm{Pd}$ catalyst was separated with an external magnet. The resulting solid was washed with water and ethanol, dried in a vacuum ovenand reused for the next time. The $\gamma-\mathrm{Fe}_{2} \mathrm{O}_{3} @ \mathrm{HAP}-\mathrm{Pd}$ was successfully recovered and reusedsixtimes without significant loss of catalytic activity $(95.1 \%$ yield initially, $94.1 \%$ yield after the sixth run).Additionally, the stability of the catalyst wasassessed by carrying out two twin experiments in whichone of them the solid catalyst was separated with an external magnetat $20 \mathrm{~min}$ reaction time, when conversion was about $60 \%$, and allowing the reaction to continue in the absence of catalyst (Figure 6). It can be seen that the experimentwithcatalyst reactedcompletely (blue line), while the other processwithout catalyst was very minor (red line), indicating that the catalyst was stable. The reaction of small amount ofaldehydecouldbe the result of the physical loss of catalytic materialduring separating. Furthermore, ICP-OES also showed the Pd content remain $2 \mathrm{wt} . \%$ after the catalystreusedsixtimes, indicating that the catalyst was stable.

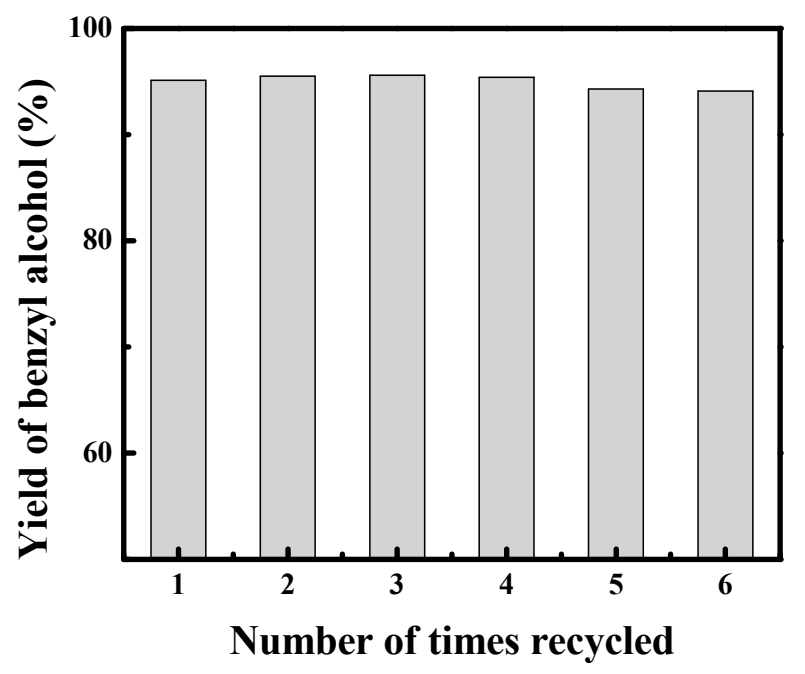

Figure 5. The results of the recycling experiments of the $\gamma-\mathrm{Fe}_{2} \mathrm{O}_{3} @ \mathrm{HAP}-\mathrm{Pd}$ catalyst. Reaction conditions: Benzaldehyde (1 mmol), $\gamma-\mathrm{Fe}_{2} \mathrm{O}_{3} @ \mathrm{HAP}-\mathrm{Pd}$ catalyst $(10 \mathrm{mg}), \mathrm{H}_{2} \mathrm{O}(10 \mathrm{~mL}), 10 \mathrm{bar} \mathrm{H}_{2}, 25^{\circ} \mathrm{C}$ and $1 \mathrm{~h}$. 


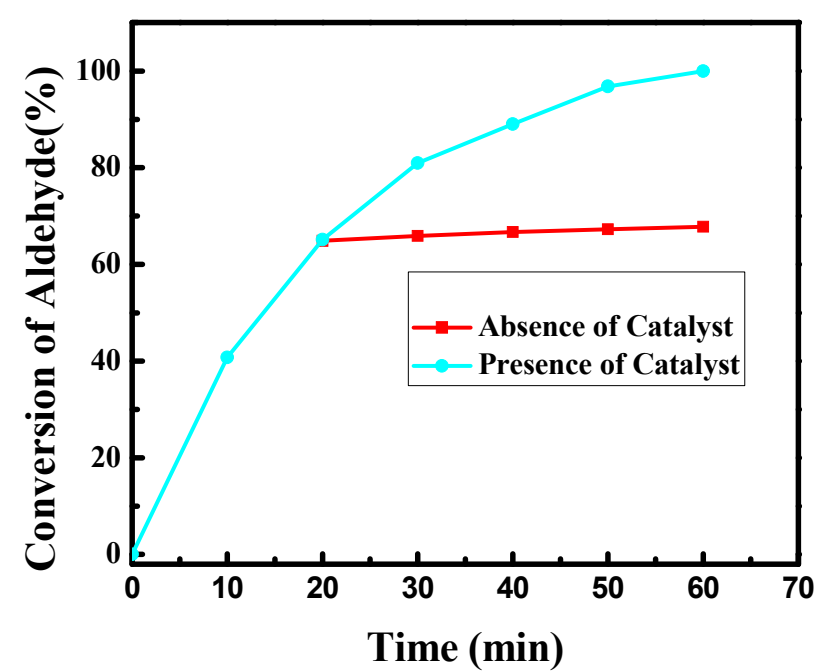

Figure 6. Plots For the hydrogenation of benzaldehyde into benzyl alcohol catalyzed by $\gamma-\mathrm{Fe}_{2} \mathrm{O}_{3} @ \mathrm{HAP}$ Pd. Reaction conditions: Benzaldehyde ( $1 \mathrm{mmol}), \gamma-\mathrm{Fe}_{2} \mathrm{O}_{3} @ \mathrm{HAP}-\mathrm{Pd}$ catalyst $(10 \mathrm{mg}), \mathrm{H}_{2} \mathrm{O}(10 \mathrm{~mL})$, 10 bar $\mathrm{H}_{2}, 25^{\circ} \mathrm{C}$, and $1 \mathrm{~h}$.

\section{Conclusions}

In conclusion, the magnetic material supported palladium catalyst $\left(\gamma-\mathrm{Fe}_{2} \mathrm{O}_{3} @ \mathrm{HAP}-\mathrm{Pd}\right)$ exhibited excellent activity and selectivity for the room-temperature hydrogenation of aldehydes under 10 bar $\mathrm{H}_{2}$ pressure. Aldehydes bearing various reducible functional groups such as ketone, halogen, nitro, orcyano groups could be reduced into corresponding alcohols with good to excellent selectivity. The deoxygenation of carbonyl compounds was successfully attained by further increasing the reaction temperature to $70{ }^{\circ} \mathrm{C}$. The hydrogenation rate of the substituted benzaldehyde showed a reasonable linear Hammett correlation and a Hammett value of 1.59 was obtained, revealing that the hydrogenation of aromatic aldehyde was substituent-sensitive and proceeded via an anionic intermediate. Furthermore, the $\gamma-\mathrm{Fe}_{2} \mathrm{O}_{3} @ \mathrm{HAP}-\mathrm{Pd}$ catalyst was shown to be recyclable up to sixtimes without any observable decrease in efficiency.

Supplementary Materials: The following are available online at http://www.mdpi.com/2076-3417/9/9/1792/s1.

Acknowledgments: The project was supported by Natural Science Foundation of China (grant no. 21606066), Anhui Provincial Natural Science Foundation (grant no. 1708085QB46), the General Project in Education Department of Anhui Province (grant no. KJ2015B1105907), Talent Research Fund Project of Hefei University (grant no. 16-17RC13).

Conflicts of Interest: The authors declare no conflict of interest.

\section{References}

1. Seemala, B.; Cai, C.M.; Kumar, R.; Wyman, C.E.; Christopher, P. Effects of Cu-Ni bimetallic catalyst composition and support on activity, selectivity and stability for furfural Cconversion to 2-methyfuran. ACS Sustain. Chem. Eng. 2018, 6, 2152-2161. [CrossRef]

2. Kogan, V.; Aizenshtat, Z.; Neumann, R. Polyoxometalates as reduction catalysts: Deoxygenation and hydrogenation of carbonyl compounds. Angew. Chem. Int. Ed. 1999, 38, 3331-3334. [CrossRef]

3. Nakagawa, Y.; Tamura, M.; Tomishige, K. Catalytic reduction of biomass-derived furanic compounds with hydrogen. ACSCatal. 2013, 3, 2655-2668. [CrossRef]

4. Kumar, B.S.; Puthiaraj, P.; Amali, A.J.; Pitchumani, K. Ultrafine Bimetallic PdCo Alloy Nanoparticles on Hollow Carbon Capsules: An efficient heterogeneous catalyst for transfer hydrogenation of carbonyl compounds. ACS Sustain. Chem. Eng. 2018, 6, 491-500. [CrossRef]

5. Chakraborty, S.; Bhattacharya, P.; Dai, H.G.; Guan, H.R. Nickel and iron pincer complexes as catalysts for the reduction of carbonyl compounds. Acc. Chem. Res. 2015, 48, 1995-2003. [CrossRef] [PubMed] 
6. Mehta, M.; Holthausen, M.H.; Mallov, I.; Perez, M.; Qu, Z.W.; Grimme, S.D.; Stephan, W. Catalytic nketone hydrodeoxygenation mediated by highly electrophilic phosphoniumcations. Angew. Chem. Int. Ed. 2015, 54, 8250-8254. [CrossRef]

7. Volkov, A.; Gustafson, K.P.J.; Tai, C.W.; Verho, O.; Bäckvall, J.E.; Adolfsson, H. Mild deoxygenation of aromatic ketones and aldehydes over Pd/C using polymethylhydrosiloxane as the reducing agent. Angezw. Chem. Int. Ed. 2015, 54, 5122-5126. [CrossRef] [PubMed]

8. Fernandes, T.A.; Bernardo, J.R.; Fernandes, A.C. Direct reductive deoxygenation of aryl ketones catalyzed by oxo-rhenium complexes. Chem CatChem 2015, 7, 1177-1183. [CrossRef]

9. Bernardo, J.R.; Fernandes, A.C. Deoxygenation of carbonyl compounds using an alcohol as an efficient reducing agent catalyzed by oxo-rhenium complexes. Green Chem. 2016, 18, 2675-2681. [CrossRef]

10. Ye, W.; Zhao, M.; Yu, Z. Ruthenium (ii) pyrazolyl-pyridyl-oxazolinyl complex catalysts for the asymmetric transfer hydrogenation of ketones. Chem. Eur. J. 2012, 18, 10843-10846. [CrossRef] [PubMed]

11. Gladiali, S.; Alberico, E. Asymmetric transfer hydrogenation: Chiral ligands and applications. Chem. Soc. Rev. 2006, 35, 226-236. [CrossRef] [PubMed]

12. Weidner, V.L.; Barger, C.J.; Delferro, M.; Lohr, T.L.; Marks, T.J. Rapid, mild and selective ketone and aldehyde hydroboration/reduction mediated by a simple lanthanide latalyst. ACSCatal. 2017, 7, 1244-1247.

13. Morris, R.H. Exploiting metal-ligand bifunctional reactions in the design of iron asymmetric hydrogenation catalysts. Acc. Chem. Res. 2015, 48, 1494-1502. [CrossRef] [PubMed]

14. Werkmeister, S.; Junge, K.; Wendt, B.; Alberico, E.; Jiao, H.; Baumann, W.; Junge, H.; Gallou, F.; Beller, M. Hydrogenation of esters to alcohols with a Well-defined iron complex. Angew. Chem. Int. Ed. 2014, 53, 8722-8726. [CrossRef]

15. Yang, P.K.; Liu, Y.W.; Chai, L.; Lai, Z.Z.; Fang, X.M.; Liu, B.Y.; Zhang, W.K.; Lu, M.H.; Xu, Y.Q.; Xu, H. Nmp-Based Ionic Liquids: Recyclable Catalysts for Both Hetero-Michael Addition and Knoevenagel Condensation in Water. Synth. Commun. 2018, 48, 1060-1067. [CrossRef]

16. Li, Z.X.; Luo, D.; Li, M.M.; Xing, X.F.; Ma, Z.Z.; Xu, H. Recyclable $\mathrm{Fe}_{3} \mathrm{O}_{4}$ Nanoparticles Catalysts for Aza-Michael Addition of Acryl Amides by Magnetic Field. Catalysts 2017, 7, 219. [CrossRef]

17. Kotha, S.S.; Sharma, N.; Sekar, G. An efficient, stable and reusable Palladium nanocatalyst: Chemoselective reduction of aldehydes with molecular hydrogen in water. Adv. Synth. Catal. 2016, 358, 1694-1698. [CrossRef]

18. Tan, J.; Cui, J.; Cui, X.; Deng, T.; Li, X.; Zhu, Y.; Li, Y. Graphene-modified Runanocatalyst for low-temperature hydrogenation of carbonyl groups. ACS Catal. 2015, 5, 7379-7384. [CrossRef]

19. Tamura, M.; Tokonami, K.; Nakagawa, Y.; Tomishige, K. Selective hydrogenation of crotonaldehyde to crotyl alcohol over metal oxide modified Ir catalysts and mechanistic insight. ACS Catal. 2016, 6, 3600-3609. [CrossRef]

20. Osako, T.; Torii, K.; Hirata, S.; Uozumi, Y. Chemoselectivecontinuous-Flow hydrogenation of aldehydes catalyzed by platinum nanoparticles dispersed in an amphiphilicresin. ACS Catal. 2017, 7, 7371-7377. [CrossRef]

21. Kalutharage, N.K.; Yi, C.S. Scope and mechanistic analysis for chemoselectivehydrogenolysis of carbonyl compounds catalyzed by a cationic ruthenium hydride complex with a tunable phenol ligand. J. Am. Chem. Soc. 2015, 137, 11105-11114. [CrossRef] [PubMed]

22. Zhang, Z.H.; Zhen, J.D.; Liu, B.; Lv, K.L.; Deng, K.J. Selective aerobic oxidation of the biomass-derived precursor 5-hydroxymethylfurfural to 2,5-furandicarboxylic acid under mild conditions over a magnetic palladium nanocatalyst. Green Chem. 2015, 1, 1308-1317. [CrossRef]

23. Yuan, Z.L.; Liu, B.; Zhou, P.; Zhang, Z.H.; Chi, Q. Aerobic Oxidation of Biomass-Derived 5-Hydroxymethylfurfural to 2,5-Diformylfuran with Cesium-Doped Manganese Dioxide. Catal. Sci. Technol. 2018, 8, 4430-4439. [CrossRef]

24. Yuan, Z.L.; Lv, K.L.; Sun, J.; Zhang, Z.H.; Chi, Q. Selective and metal-free oxidation of biomass-derived 5-hydroxymethylfurfural to 2,5-diformylfuran over nitrogen-doped carbonmaterials. Green. Chem. 2018, 20, 4946-4956.

25. Xu, X.; Li, Y.; Gong, Y.T.; Zhang, P.F.; Li, H.R.; Wang, Y. Synthesis of palladium nanoparticles supported on mesoporous N-doped carbon and their catalytic ability for biofuel upgrade. J. Am. Chem. Soc. 2012, 134, 16987-16990. [CrossRef] [PubMed] 
26. Shen, Y.; Bo, X.K.; Tian, Z.F.; Wang, Y.Z.; Guo, X.K.; Xie, M.J.; Gao, F.; Lin, M.; Guo, X.F.; Ding, W.P. Fabrication of highly dispersed/active ultrafine Pd nanoparticle supported catalysts: a facile solvent-free in situ dispersion/reduction method. Green Chem. 2017, 19, 2646-2652. [CrossRef]

27. Sever, R.; Root, T.W. DFT study of solvent coordination rffects on titanium-basedepoxidationcatalysts. Part One: Formation of the titanium hydroperoxointermediate. J. Phys. Chem. B 2003, 107, 4080-4089. [CrossRef]

28. Ouyang, R.H.; Jiang, D.E. Understanding selective hydrogenation of $\alpha, \beta$-unsaturated ketones to unsaturated alcohols on the $\mathrm{Au}_{25}(\mathrm{SR})_{18}$ cluster. ACSCatal. 2015, 5, 6624-6629.

29. Chen, J.Z.; Liu, R.L.; Guo, Y.Y.; Chen, L.M.; Gao, H. Selective hydrogenation of biomass-based 5-hydroxymethylfurfural over catalyst of Palladium immobilized on amine-functionalized Metal-Organic Frameworks. ACS Catal. 2015, 5, 722-733. [CrossRef]

30. Heiba, E.I.; Dessau, R.M.; Koehl, W.J. Oxidation by metal salts. III. Reaction of manganic acetate with aromatic hydrocarbons and the reactivity of the carboxymethylradical. J. Am. Chem. Soc. 1969, 91, 138-145. [CrossRef]

31. Fukui, M.; Tanaka, A.; Hashimoto, K.; Kominami, H. Visible light-induced heterogeneous Meerwein-Ponndorf-Verley-type reduction of an aldehyde group over an organically modified titanium dioxide photocatalyst. Chem. Comm. 2017, 53, 4215-4218. [CrossRef] [PubMed]

(C) 2019 by the authors. Licensee MDPI, Basel, Switzerland. This article is an open access article distributed under the terms and conditions of the Creative Commons Attribution (CC BY) license (http://creativecommons.org/licenses/by/4.0/). 